\title{
ANÁLISE DE EFICIÊNCIA TÉRMICA DOS MOTORES AERONÁUTICOS TURBOFAN
}

\author{
Daniel Assunção dos Santos ${ }^{1}$ \& Vitor Emmanuel Andrade ${ }^{2}$
}

\begin{abstract}
RESUMO
ASSUNÇÃO, D. S.; ANDRADE, V. E. Análise de eficiência térmica dos motores aeronáuticos Turbofan. Perspectivas Online: Exatas \& Engenharia, v.11, n.34, p.18-43, 2021.

Este artigo versa, no sentido amplo, em apresentar uma análise sobre fatores internos e externos que afetam o comportamento do motor e seu desempenho em termos térmicos, além de uma análise de eficiência, a partir da razão entre variação da energia cinética do fluido e a potência química do combustível, equação essa muito aplicada pelos engenheiros aeronáuticos sobre o tipo de motor mais presente, hoje, no mercado da aviação comercial: os Turbofans. Para tal abordagem, foi utilizado o software Gasturb 13, uma ferramenta muito aplicada nas academias e indústrias para projeto de motores aeronáuticos. Nele, serão inseridas premissas, obtidas em materiais disponibilizados no domínio público, como: dissertações, livros e sites de fabricantes (Rolls Roice, GE Aviation, Safran entre outros), além de pesquisas e

dos modelos ideais de ciclos termodinâmicos determinados por grandes nomes, a exemplo, o engenheiro americano George Bailey Brayton, que traz fortes contribuições para o entendimento das turbinas a gás. Os resultados apontaram que para parâmetros de velocidade de fluxo, em números de mach próximos de 0.8 , e condições atmosféricas em altitudes de cruzeiro (entre 9,1 e 12,4 km), o motor Turbofan apresenta respostas de grande eficiência térmica para uma dada temperatura de entrada de turbina fixa em $2.916 \mathrm{R}\left(1.396,85{ }^{\circ} \mathrm{C}\right)$, além da forte influência do potencial calorífico inferior do combustível e sangrias de ar do compressor na eficiência térmica do ciclo. Respostas estas que autenticam a confiabilidade do software para análise de desempenho e cálculos de turbinas aeronáuticas.
\end{abstract} aprofundamentos essenciais como o estudo

Palavras-chave: Termodinâmica. Aeronáutica. Eficiência Térmica.

\footnotetext{
${ }^{1}$ Faculdade de Ciência e Tecnologia ÁREA 1 - WYDEN, Av. Luís Viana Filho, 3172 - Paralela, Salvador, BA, CEP: 41720-200, Brasil.

(*) e-mail: daniel.assuncao.2011@gmail.com

Data de recebimento: 09/11/2021. Aceito para publicação: 13/12/2021. Data de publicação: 21/12/2021.
} 
Revista Perspectivas Online: Exatas \& Engenharia

Dezembro/2021, v.11, n.34, p. 18- 43

ISSN: 2236-885X (Online)

DOI: $10.25242 / 885 X 113420212349$

\title{
THERMAL EFFICIENCY ANALYSIS OF TURBOFAN AERO ENGINES
}

\author{
Daniel Assunção dos Santos ${ }^{1}$ \& Vitor Emmanuel Andrade ${ }^{2}$
}

\begin{abstract}
ASSUNÇÃO, D. S.; ANDRADE, V. E. Thermal efficiency analysis of turbofan aero engines. Perspectivas Online: Exatas \& Engenharia, v.11, n.34, p.18-43, 2021.
\end{abstract}

This article aims to present a broad analysis of internal and external factors that affect the engine behavior and its performance in thermal terms, in addition to an efficiency analysis from the ratio between the variation of the fluid's kinetic energy and the fuel's chemical power, an equation widely applied by aeronautical engineers on the type of engine most present today in the commercial aviation market: the Turbofans. For this approach, the Gasturb 13 software was used, a tool widely used in academies and industries for the design of aero engines. In it will be inserted assumptions obtained from materials available in the public domain such as dissertations, books and websites of manufacturers such as Rolls Roice, GE Aviation, Safran among others, in addition to research and essential deepening as the study of ideal models of thermodynamic cycles determined by great names such as the American engineer George Bailey Brayton, who brings strong contributions to the understanding of gas turbines. The results pointed out that for flow velocity parameters, at mach numbers close to 0.8 , and atmospheric conditions at cruising altitudes (between 9.1 and $12.4 \mathrm{~km}$ ) the Turbofan engine shows high thermal efficiency responses for a given turbine inlet temperature fixed at $2,916 \mathrm{R}$ $\left(1,396.85{ }^{\circ} \mathrm{C}\right)$. In addition to the strong influence of the lower calorific potential of the fuel and compressor air bleeds on the thermal efficiency of the cycle. These answers authenticate the reliability of the software for aeronautical turbine performance analysis and calculations.

Keywords: Thermodynamics, aeronautics, Thermal Efficiency.

\footnotetext{
${ }^{1}$ Graduando do Curso de Engenharia Mecânica da Faculdade de Ciência e Tecnologia ÁREA 1 - WYDEN;

${ }^{2}$ Professor orientador do Trabalho de Conclusão de Curso, de Engenharia Mecânica da Faculdade de Ciência e Tecnologia ÁREA 1.

(*) e-mail: daniel.assuncao.2011@gmail.com
}

Persp. Online: exatas \& eng., Campos dos Goytacazes, 34(11) $18-43-2021$

https://ojs3.perspectivasonline.com.br/ 
Received: 09/11/2021. Accepted:.13/12/2021 Published online: 21/12/2021.

\section{INTRODUÇÃO}

Descartes (1637) propõe, como método analítico, um processo pelo qual é aplicado um raciocínio (caminho), de modo a decompor um todo em partes - mais simples - que a constitui.

Fatores de eficiência podem ser entendidos com a ação de pedalar uma bicicleta, onde o corpo exerce uma força sobre os pedais e, segundo a terceira Lei de Newton, da ação e reação, esta força é transferida até os pneus (por meio dos componentes de transmissão) que entram em contato com o solo e, a partir da força de atrito, convertem parte da energia no movimento (para frente) da bicicleta. Contudo, uma parte da energia gerada é dissipada em outras formas de energia, devido a diversas variáveis, como: atritos indesejáveis, peso dos componentes, entre outras, que acabam contribuindo, direta ou indiretamente, no prejuízo da transformação da energia aplicada em trabalho efetivo. Desta forma, é possível definir a eficiência deste processo como a capacidade de transformação da energia gerada pelo ciclista em movimento - para frente - com o mínimo de dissipação (prejuízo) possível de energia. Em máquinas térmicas, a base conceitual é a mesma, a eficiência térmica se baseia na capacidade de uma energia fornecida, sendo esta, em forma de calor, pela fonte quente ser transformada em trabalho mecânico com menor dissipação possível de energia para a fonte fria.

Essa ideia é fundamentada pela segunda lei da termodinâmica, a qual pode ser definida segundo as propostas do físico, matemático e engenheiro britânico William Thompsom (1824-1907) e o também físico alemão Max Planck (1848-1947), os quais afirmam: "É impossível construir uma máquina térmica que, ao operar em ciclos transforme integralmente em trabalho mecânico todo calor que fornece", sendo parte deste calor transformado em outras formas de energia como a interna, a cinética e a potencial do gás.

Em termos de cálculo, a eficiência térmica $\left(\eta_{t h}\right)$ de qualquer motor térmico é definida como a razão entre o trabalho $(W)$ e a entrada de calor $\left(Q_{\text {inicial }}\right)$. Para calcular a eficiência térmica, os engenheiros costumam usar entalpia (SAFRAN, 2011).

O estudo da Eficiência Térmica é fundamental para a evolução das turbinas a gás, que se deparam com diversas variáveis que, por sua vez, contribuem para o prejuízo da transformação. É possível citar:

- Temperatura de entrada da turbina;

- Razão de pressão total;

- Eficiência dos Componentes;

- Tecnologia de resfriamento.

O objetivo deste artigo é, por meio de fatores térmicos, elucidar o conhecimento sobre o comportamento dos gases em motores a jato, os quais se caracterizam, em linhas gerais, por seu efeito propulsivo, a partir da reação ao deslocamento da massa de ar para traz (segundo os princípios da terceira lei de Newton) definindo-se assim os motores Turbojatos. No caso dos Turbofans, se baseiam em motores tipo turbojato, contudo, com uma grande hélice frontal (fan blade) que impulsiona o ar tanto para os compressores menores quanto para os dutos externos, ou seja, uma razão de by-pass a qual é responsável por praticamente todo o empuxo da aeronave. Na Figura 1 são apresentadas as configurações básicas dos motores Turbojato e Turbofan:

Persp. Online: exatas \& eng., Campos dos Goytacazes, 34(11) $18-43-2021$

https://ojs3.perspectivasonline.com.br/ 


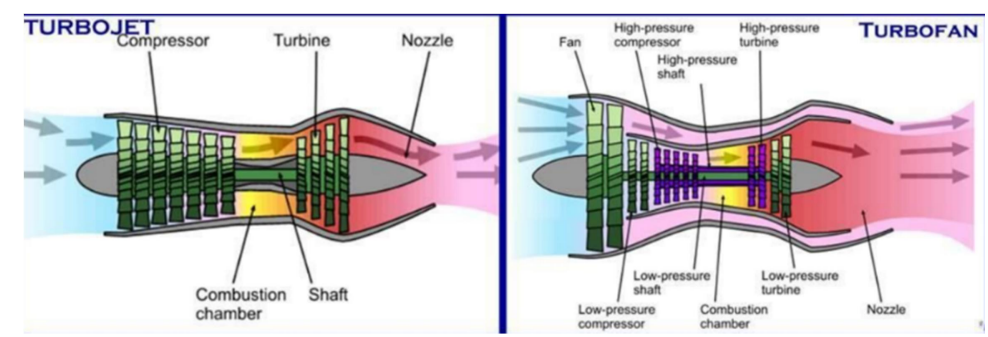

Figura 1 - Sistema de motores Turbojato e Turbofans. (Fonte: Nihonkoku Shoukan Wiki, 2021).

Com isso, objetiva-se caracterizar fatores de eficiência do processo em um volume de controle (região delimitada para a realização da análise) que compreende desde o ar admitido pelo sistema, até a sua exaustão, além de fatores externos que interferem no seu comportamento.

Uma forte contribuição ao estudo da eficiência das turbinas a gás é a realizada pelo engenheiro Brayton (1830-1892), que formula um ciclo com seu nome que até hoje é a base para o funcionamento dos motores aeronáuticos deste tipo:

$\mathrm{O}$ ar fresco em condição ambiente é ingerido pelo compressor, onde o ar é comprimido isentropicamente. Durante esta fase, o trabalho é feito no sistema. Durante este processo, a pressão e a temperatura da substância de trabalho aumentam, enquanto o volume é reduzido. A alta pressão segue para a câmara de combustão, onde o combustível é queimado a pressão constante. Devido ao aquecimento de pressão constante, a temperatura e o volume da substância de trabalho aumentam. Os gases resultantes de alta temperatura então entram na turbina, onde se expandem à pressão atmosférica isentropicamente, isso produzindo a energia (J. S. RAJADURAI, 2003, p.12).

Definindo assim o chamado ciclo aberto de Brayton, já que, apesar do sistema retornar às condições iniciais, configurando um ciclo, a massa do sistema não é "recirculada". Esse esquema é apresentado na Figura 2, onde é especificando as saídas $\left(\mathrm{w}_{\mathrm{T}}\right)$ e entradas $\left(\mathrm{W}_{\mathrm{P}}\right)$ de trabalho:

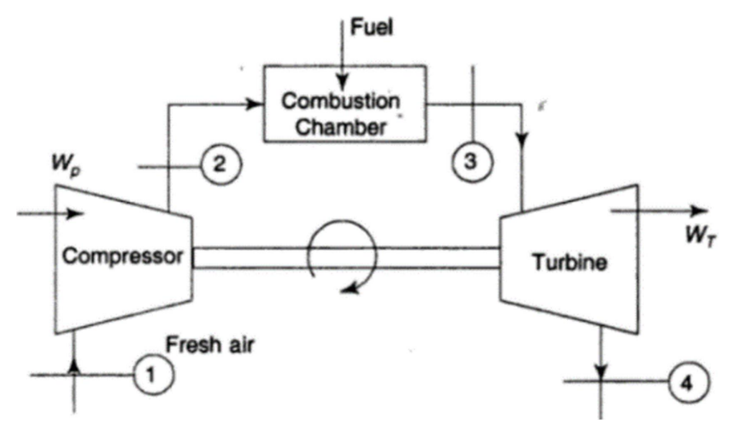

Figura 2 - Ciclo Aberto de Brayton. (Fonte: Rajadurai, p.12, 2003).

Um ciclo fechado é definido pelas mesmas razões de compressão e expansão, contudo a rejeição de calor a uma pressão constante substitui a exaustão.

\section{MODELOS IDEAIS}

Persp. Online: exatas \& eng., Campos dos Goytacazes, 34(11) 18 -43-2021

https://ojs3.perspectivasonline.com.br/ 
Um modelo termodinâmico ideal pode ser definido como considerações analíticas que possibilitam uma compreensão simplificada de um processo real, sendo essas considerações, definidas de acordo com a conveniência da análise, buscando sempre uma menor divergência possível do comportamento real.

Para o ciclo de Brayton (já descrito acima), ou também chamado de ciclo ideal das turbinas a gás, algumas considerações são extremamente importantes durante o processo, algumas delas, chamadas de transformações termodinâmicas.

Uma análise do ciclo com foco nessas transformações pode ser expressa da seguinte forma: o ar é admitido pelo difusor do motor (duto de entrada) e direcionado para os compressores, onde são submetidos a uma compressão isentrópica, ou seja, uma compressão sem troca de calor com o meio externo (adiabática) e de forma reversível. A reversibilidade que se dá a partir de uma transformação sem a ocorrência de nenhum fenômeno dissipativo, que pode ser gerado, por exemplo, pela perda de carga do fluido e por atritos internos. Esta compressão gera, no diagrama P-V (Figura 3), uma curva hiperbólica devido a aplicação da equação dos gases ideais. No combustor, o ar é submetido a uma combustão isobárica, ou seja, à pressão constante, para isso considera-se que a câmara de combustão se localiza externamente ao duto de passagem do gás, sendo o duto apenas um trocador de calor que eleva a temperatura do fluido, elevando também a temperatura do sistema. Seguindo para as turbinas, onde se tem uma expansão isentrópica, nelas, ocorrem perdas de pressão e temperatura, transformando o calor em trabalho mecânico. Por fim, parte do calor é rejeitado para a atmosfera, a uma pressão constante, retornando, hipoteticamente, às mesmas condições ambientes da admissão.
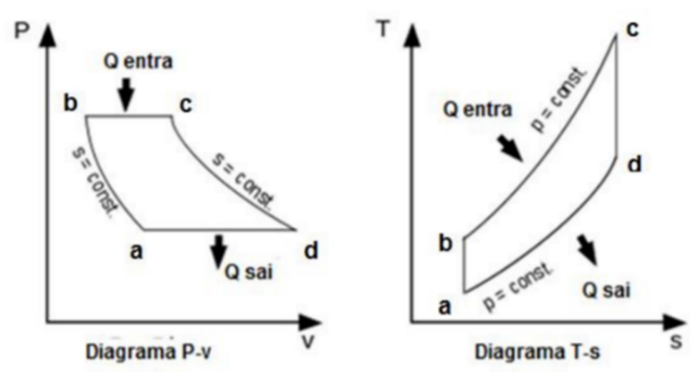

Figura 3 - Diagramas P-V e T-s. (Fonte: Shapiro \& Moran, 2009).

Apossando-se da primeira lei da termodinâmica, é possível obter, além do fluxo de energia em forma de calor e trabalho, um fluxo mássico de um gás ideal, onde é aplicado o princípio da conservação e a suposição de que toda a massa do sistema permanece constante (escoamento permanente), ou seja, durante o processo, a quantidade de massa que entra no volume de controle $\left(\dot{m}_{1}\right)$ é igual ao que sai $\left(\dot{m}_{2}\right)$, ao longo do tempo. Desta forma, é obtido a equação:

$$
\dot{Q}-\dot{w}=\sum_{\text {sai }} \dot{m} \dot{\theta}-\sum_{\text {entra }} \dot{m} \dot{\theta}
$$

Onde $\theta$ é a energia total dissipada pelo sistema em termos de energia interna, cinética e potencial. Atribuindo os termos da energia potencial, chega-se à seguinte equação:

Persp. Online: exatas \& eng., Campos dos Goytacazes, 34(11) $18-43-2021$

https://ojs3.perspectivasonline.com.br/ 


$$
\dot{Q}-\dot{w}=\dot{m}\left(h+\frac{V^{2}}{2}+g z\right)_{s a i}-\dot{m}\left(h+\frac{V^{2}}{2}+g z\right)_{e n t r a}
$$

Nesta equação é apresentada uma nova variável, a entalpia, que é caracterizada como um nível energético e que pode ser calculada pela somatória entre a energia interna $u$ e o produto da pressão e volume: $h=u+P v$. Importante ressaltar que os termos em letras minúsculas, descritos nas fórmulas acima, são valores específicos, ou seja, sobre unidade de massa $(/ \mathrm{kg})$. A partir da equação anterior pode-se definir o trabalho realizado pelos compressores e turbinas, assim como a transferência da energia interna, para um fluido de gás ideal, em regime permanente.

Analisando (a-b), onde o gás é comprimido isentropicamente $(\dot{Q}=0)$, é possível aplicar a primeira lei para determinar o trabalho realizado pelo compressor, desconsiderando a diferença desprezível de energia cinética e potencial gravitacional de entrada e saída do gás no volume de controle:

$$
\dot{w}_{c o m p}=\dot{m}_{a r}\left(h_{b}-h_{a}\right)
$$

Para a turbina (c-d), com as mesmas considerações feitas no compressor, é obtido a seguinte expressão:

$$
\dot{w}_{t u r b}=\dot{m}_{a r+c o m b}\left(h_{c}-h_{d}\right)
$$

No combustor (b-c), onde é realizada a injeção de calor a uma pressão constante, não há trabalho de fronteira. Desconsiderando as variações de energia potencial e cinética, o calor líquido que entra no sistema pode ser definido como:

$$
\dot{Q}_{C o m b}=\dot{m}_{a r+c o m b}\left(h_{c}-h_{b}\right)
$$

Segundo Shapiro \& Moran (2009), a eficiência isentrópica envolve uma comparação entre o desempenho real e o desempenho em condições ideais de uma turbina ou de um compressor. Com isso, a eficiência na turbina e no compressor pode ser definida da seguinte forma:

$$
\begin{gathered}
\eta_{c}=\frac{\left(\dot{w}_{c} / \dot{m}\right)_{i}}{\dot{w}_{c} / \dot{m}}=\frac{\left|h_{b i}-h_{a}\right|}{\left|h_{b}-h_{a}\right|} \\
\eta_{t}=\frac{\dot{w}_{t} / \dot{m}}{\left(\dot{w}_{t} / \dot{m}\right)_{i}}=\frac{h_{c}-h_{d}}{h_{c}-h_{d i}}
\end{gathered}
$$

O subscrito $(i)$ entende-se pela entalpia do ponto, em um processo adiabático e reversível, ou seja, isentrópico. Desta forma, é possível definir a eficiência térmica do ciclo ideal de Brayton como a razão entre a variação de trabalho de fluxo e o calor inserido no sistema:

$$
\eta_{t h}=\frac{\dot{w}_{t u r b}-\dot{w}_{c o m p}}{\dot{Q}_{C o m b}}
$$

Em termos de entalpia, como é considerado por muitos engenheiros por encontrar estes valores tabelados, tem-se:

Persp. Online: exatas \& eng., Campos dos Goytacazes, 34(11) $18-43-2021$

https://ojs3.perspectivasonline.com.br/ 


$$
\eta_{t h}=\frac{\left(h_{c}-h_{d}\right)-\left(h_{b}-h_{a}\right)}{h_{c}-h_{b}}
$$

\section{PARÂMETROS DE PROJETO DE UM MOTOR AERONÁUTICO}

Um ponto de projeto é um parâmetro de referência para análise do comportamento e construção de cada componente, onde todas as condições de operação são definidas e conhecidas. Normalmente, os projetistas costumam utilizar pontos, como: Decolagem, Subida e Máximo Contínuo - este último definido pela ASSOCIAÇÃO BRASILEIRA DE NORMAS TÉCNICAS. NBR 15971-4, como o empuxo estático (potência equivalente total) desenvolvido nas condições máximas de operação, aprovado para uso por períodos sem restrição de duração - ou seja, pontos de regimes de alta potência que funcionam como parâmetros de projeto.

Segundo Avellan (2011), em termos de temperatura de ciclo, o Thermal Design Point (TDP) é a condição mais demandante do envelope de voo. Tipicamente uma condição de decolagem em alto e quente, ou um cruzeiro monomotor, em máximo contínuo.

Analisando os componentes com base em um Turbofan de dois eixos (CFM56-7B) de onde se pode derivar outras arquiteturas de motores aeronáuticos, é possível dividir o motor em cinco principais partes que o compõe:

- Difusor de Admissão;

- Fan

- Compressores (baixa e alta)

- Combustor

- Turbinas (baixa e alta)

- Exaustor

Utilizando o padrão de numeração de estações disposto na norma SAE ARP 755D (Figura 4), que serve como parâmetro para garantir a comunicação entre as interfaces dos componentes, pode-se identificar os diversos pontos de análise que envolve entrada e saída dos principais componentes:

Persp. Online: exatas \& eng., Campos dos Goytacazes, 34(11) $18-43-2021$

https://ojs3.perspectivasonline.com.br/ 
- Padronização de estações


Figura 4 - Padronização de Estágios (Fonte: Adaptado de SAE ARP 755D, 2014)

O primeiro se baseia em um duto ou bocal de admissão, por onde os gases são direcionados para o interior do motor, podendo ser identificado da estação 0 a 12 ou a 22 nas estações padronizadas e na região em destaque da Figura 5:

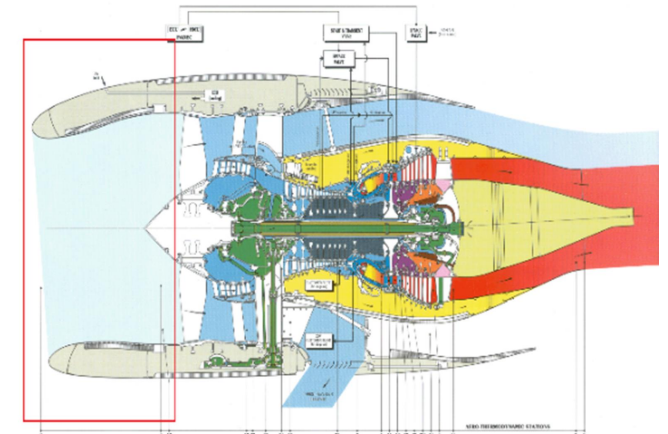

Figura 5 - Motor CFM56-7B, difusor. (Fonte: Adaptado de DOKUMEN.TIPS, 2021).

De acordo com Reis (2015), esses dutos de admissão são projetados para desacelerar o escoamento até alcançar velocidades axiais apropriadas, a partir do aumento da área de passagem, ou seja, um duto divergente - em regime subsônico $($ Mach $<1)$ - aumentando a pressão estática, de modo a melhorar o desempenho do fan ou dos compressores.

Para tanto, é possível apontar alguns parâmetros de projeto, como eficiência isentrópica e Perda de Pressão Total. Segundo Shapiro \& Moran (2009), a eficiência isentrópica de um bocal é definida como a razão entre a energia cinética específica do gás, saindo do bocal, e a energia cinética na descarga do bocal que é atingida em uma expansão isentrópica entre o mesmo estado de admissão e a mesma pressão de descarga. Para o bocal de admissão tem-se o inverso:

$$
\eta_{d}=\frac{\left(V_{2}{ }^{2} / 2\right)_{i}}{{V_{2}}^{2} / 2}
$$

Em termos de temperatura ou pressão, é possível reescrever a equação da seguinte forma:

Persp. Online: exatas \& eng., Campos dos Goytacazes, 34(11) $18-43-2021$

https://ojs3.perspectivasonline.com.br/ 


$$
\eta_{d}=\frac{T_{2 i}-T_{0 s}}{T_{2}-T_{0 s}}=\frac{\left(\frac{P_{2}}{P_{0 s}}\right)^{\left(\frac{\gamma-1}{\gamma}\right)}-1}{\left(\frac{\gamma-1}{2}\right) M^{2}}
$$

Onde $\gamma$ é a relação de calores específicos e $M$ é o número de $M a c h$, um parâmetro multiplicador da velocidade do som definido pela expressão:

$$
M=\frac{\text { velocidade do escoamento }}{\text { velocidade do som }}=\frac{c}{a}
$$

Onde $a$, considerando a análise de um gás ideal, pode ser definido como:

$$
a=\sqrt{y R T}
$$

Já a razão de pressão total do difusor é definida pela divisão entre a pressão na entrada do $\operatorname{fan}\left(P_{2}\right)$ e a pressão atmosférica $\left(P_{0}\right)$.

No fan, identificado entre as estações 2 ou 12 até 13 ou 22 na padronização, alguns pontos de projeto são bastante semelhantes aos dos compressores, já que, diferentemente das hélices de um turboélice que tem a função de gerar velocidade ao escoamento e assim gerar tração, esses fans funcionam como um compressor auxiliar, composto por rotor (fan blade), responsável pelo aumento da pressão total (pressão dinâmica), e estator (Outlet Guide Vane), que funciona como um difusor, transformando a pressão dinâmica em pressão estática.

Os gases do fan, como já explicado, alimentam tanto os compressores, combustor e turbinas, quanto o duto de by-pass que integra um bocal de exaustão. Essas fan blades, por terem maiores diâmetros, apresentam uma maior eficiência e tem como alguns parâmetros de projeto a Razão de pressão total (FPR - Fan Pressure Ratio), Razão de passagem (BPR Bypass Ratio), número de estágios e eficiência isentrópica. Para fins térmicos, o fan tem um papel de aumentar a pressão pela sua base $(2-22)$ que alimenta os compressores de baixa pressão, elevando a razão de pressão total (OPR - Overall Pressure Ratio), especificado na Figura 4, entre as estações 2 e 3, contribuindo para a eficiência térmica do ciclo. A expressão que fornece o aumento de temperatura em razão da eficiência isentrópica do $\operatorname{fan}\left(\eta_{f, i}\right)$ é dada como:

$$
T_{22}=T_{2}\left\{1+\frac{1}{\eta_{f, i}}+\left[\left(\frac{P_{22}}{P_{2}}\right)^{\left(\frac{\gamma-1}{\gamma}\right)}-1\right]\right\}
$$

Da mesma forma, pode-se obter a Temperatura de saída do fan dos estágios 12 para 13, para termos de pressão $P_{12}$ e $P_{13}$. Com isso, é possível concluir que quanto mais eficiente o fan, menor a temperatura de saída.

Partindo para os próximos compressores, que, no caso do motor CFM56-7B, são divididos em Compressores de Baixa Pressão (LPC - Low pressure compressor, ou também chamado Booster) e os de Alta Pressão (HPC - Hight pressure compressor), identificado na padronização entre os estágios 22 e 3 . Esses componentes são considerados pelos engenheiros como o coração do motor, por ser responsável por grande parte de sua eficiência.

Persp. Online: exatas \& eng., Campos dos Goytacazes, 34(11) $18-43-2021$

https://ojs3.perspectivasonline.com.br/ 
Assim como no fan, cada estágio dos compressores é composto por um rotor (rotating blades) e um estator (stationary vanes) com as mesmas finalidades dos rotores e estatores do fan, todavia em razões maiores de compressão devido a diminuição da área axial que eleva a densidade do fluido, e interferindo em fatores termodinâmicos do escoamento, como mostrado na tabela 1:

Tabela 1 - Propriedades Termodinâmicas do escoamento no Compressor. Fonte: Walsh \& Fletcher (2004)

\begin{tabular}{ccc}
\hline Propriedades & Rotor & Estator \\
\hline Pressão Estática & Acréscimo & Acréscimo \\
Pressão total & Acréscimo & Pequeno decréscimo \\
Temperatura Estática & Acréscimo & Acréscimo \\
Temperatura total & Acréscimo & Constante \\
Velocidade Absoluta & Acréscimo & Decréscimo \\
Entalpia & Acréscimo & Constante \\
Densidade & Acréscimo & Acréscimo \\
\hline
\end{tabular}

O princípio de operação do compressor é realizado da seguinte forma:

Durante a operação, o rotor é girado em alta velocidade pela turbina para que o ar seja continuamente induzido no compressor, que é então acelerado pelas lâminas rotativas e varrido para trás na fileira adjacente de palhetas do estator. $\mathrm{O}$ aumento de pressão resulta da energia transmitida ao ar no rotor que aumenta a sua velocidade. $\mathrm{O}$ ar é então desacelerado (difundido) na seguinte passagem do estator e a energia cinética traduzida em pressão. As palhetas do estator também servem para corrigir a deflexão dada ao ar pelas lâminas do rotor e para apresentar o ar no ângulo correto para a próxima fase de lâminas. A última linha de palhetas do estator geralmente atuam como guias, que "ordenam" o fluxo de ar removendo redemoinhos antes da entrada no sistema de combustão em uma velocidade axial razoavelmente uniforme (ROLLS ROICE, 1986).

É possível visualizar o comportamento do fluido em termos de velocidade e pressão, diagramaticamente, na Figura 6:



Figura 6 - Pressão e velocidade durante os estágios de rotor e estator em um motor axial.

(Fonte: ROLLS ROYCE, 1986).

A complexidade de projeto no funcionamento de compressores é bastante elevada, em especial no HPC, devido a mecanismos de perda, como: dissipação viscosa do fluido, já que, em condições reais, o fluido interage fortemente com as paredes do componente e com os

Persp. Online: exatas \& eng., Campos dos Goytacazes, 34(11) $18-43-2021$

https://ojs3.perspectivasonline.com.br/ 
aerofólios, o que eleva os termos de rugosidade superficial relativa, aumentando o arrasto do motor e diminuindo a sua eficiência; ondas de choque, que são provocadas por elevação da velocidade do escoamento nas pontas das blades a números próximos da velocidade do som; e escoamentos secundários devido às folgas de topo (folga necessárias nas pontas das pás que permite o movimento rotacional sem atrito sólido). Estes fatores levam a grandes desafios no seu desenvolvimento, que tem como alguns dos principais parâmetros: razão de pressão total, número de estágios, eficiência isentrópica e temperatura de saída. Este último é, muitas vezes, limitado pela temperatura de fusão do material, por esta razão, comumente, utiliza-se ligas de titânio por apresentar uma resistência a temperaturas de quase $1700^{\circ} \mathrm{C}$ sem se fundir. $\mathrm{O}$ número de estágios de um compressor, por sua vez, está fortemente relacionado à razão de pressão total e temperatura de entrada do ciclo, como mostrado no gráfico da Figura 7:

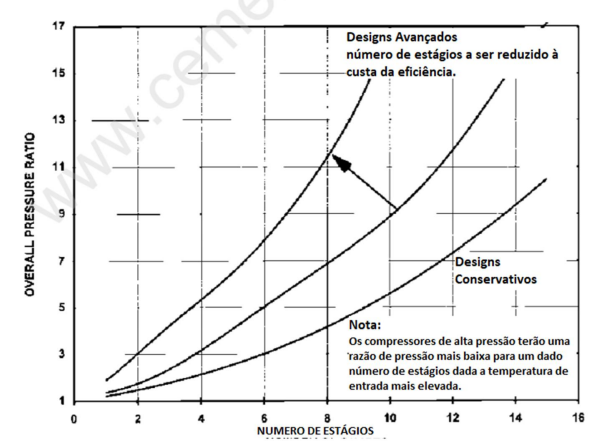

Figura 7 - Número de estágios versus OPR. (Fonte: Walsh \& Fletcher, 2004).

Diferente das turbinas, os compressores são componentes que atribuem ao fluido uma ação não espontânea de fluxo, pois ele tem a missão de retirar o gás de um estado de "maior desordem", injetando energia por meio de trabalho de eixo. Por isso, um grande desafio dos projetistas é manter o fluxo contínuo do ar sem causar o fenômeno do estol.

Para Walsh \& Fletcher (2004), a uma dada velocidade, as filas de aerofólio podem estolar, ou seja, o fluxo separa-se da superfície de sucção, à medida que a relação de pressão e, consequentemente, a incidência aumentam. Ainda segundo eles, em um aerofólio, o ponto de estol é definido como a incidência em que o coeficiente de perda de pressão do aerofólio atinge o dobro do seu valor mínimo. Se a paragem da rotação dos compressores se tornar severa, ou for introduzida subitamente, como no caso da injeção de objetos danosos (F.O.D Foreign Object Debris), pode resultar numa série de regimes de fluxo inaceitáveis, como surtos em toda a gama de velocidade, caso os componentes circundantes obriguem o ponto de operação do compressor a subir uma linha especulada, de tal forma que a relação de pressão seja aumentada para a linha denominada de Linha de Surge. Essa margem pode ser vista na Figura 8.

Esse fenômeno afeta, consideravelmente, o fluxo de ar, na taxa de compressão e eficiência do componente, podendo causar explosões internas devido tanto à baixa vazão mássica de ar nos combustores, o que provoca uma queima secundária do combustível no encontro com os gases de escape do duto de bypass, quanto pela extrema temperatura do combustor devido à ausência de ar suficiente para o seu resfriamento. 


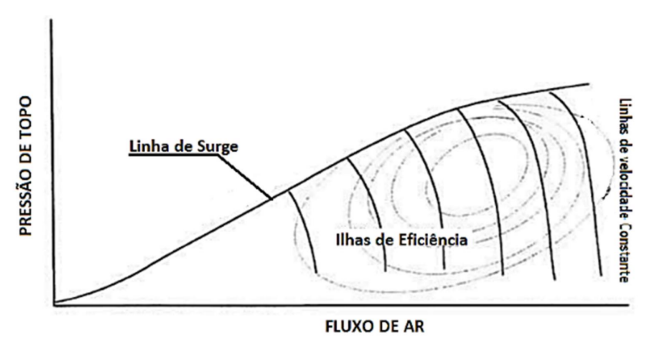

Figura 8 - Curva de Performance do compressor axial. (Fonte: Adaptado de Giampaolo, 2020).

Uma medida para evitar o estol de compressor é adotada nos motores tradicionais britânicos, sendo, tais motores, compostos por três eixos (Figura 9a): compressores de baixa (LPC), intermediário (IPC) e de alta pressão (HPC), proporcionando rotações mais adequadas para cada regime de compressão. Este controle de estol pode ser feito também com o auxílio de palhetas-guia de entrada variável (VIGVs - Variable Inlet Guide Vanes), para o primeiro estágio, e palhetas estatoras variáveis (VSV - Variable Stator Vanes), para os estágios seguintes (Figura 9b), que como o próprio nome sugere, atua como variadoras de geometria do estator, regulando a incidência de ar à medida que a relação de pressão do eixo é aumentada. Contudo, esses artifícios costumam afetar consideravelmente o peso e o custo de fabricação do motor, por isso as VSVs são utilizadas apenas nos três ou quatro primeiros estágios do compressor de alta pressão.
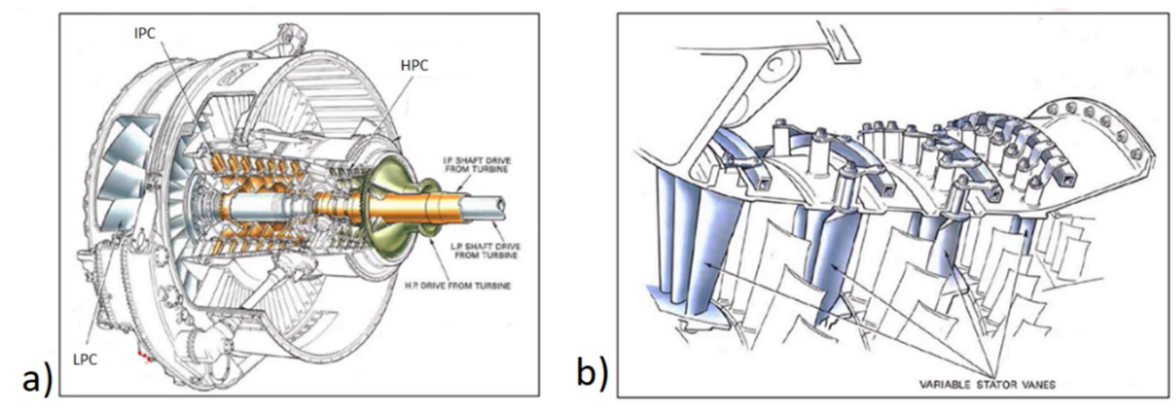

Figura 9 - (a) Motor de três eixos e (b) VSVs. (Fonte: Adaptado de ROLLS ROYCE, 1986)

Um outro meio de evitar as condições de estol do compressor é o emprego de válvulas de alívio, de modo a sangrar parte do ar que passa pelos compressores, com o intuito de diminuir a pressão. Segundo Ribeiro (2012), no motor CFM56-7B, o caudal de ar nos compressores é controlado por 12 válvulas de bleed (VBVs - Variable Bleed Valves), as quais estão localizadas, circunferencialmente, na estrutura da fan, entre o booster e o HPC. Contudo, esse recurso diminui, consideravelmente, a razão de pressão total do sistema, impactando no consumo específico do motor, comprometendo a eficiência do ciclo. Por isso, essas válvulas de sangria são normalmente utilizadas em regimes de baixa potência.

O principal objetivo dos compressores é entregar o gás em melhores condições possíveis para o combustor, localizado pelo sistema de padronização internacional entre as estações 3 e 4 . Como visto, em um sistema idealizado, o combustor tem a função de elevar a temperatura do gás à pressão constante. Contudo, em condições reais, é possível perceber uma pequena perda de pressão total do ar devido a uma elevação no diâmetro de entrada da cabine em relação ao diâmetro de entrega dos compressores, de modo a alimentar o combustor de forma otimizada para a queima.

Persp. Online: exatas \& eng., Campos dos Goytacazes, 34(11) $18-43-2021$

https://ojs3.perspectivasonline.com.br/ 
Além disso, existem alguns mecanismos de perda identificados durante o percurso do fluxo de ar, como: os efeitos da viscosidade (fricção do fluido que escoa sobre a superfície), a própria característica de irreversibilidade do processo de combustão, além da turbulência e separação dos gases realizados com o intuito de aumentar a eficiência da queima.

Em funcionamento normal, a razão ar/combustível global de uma câmara de combustão pode variar entre 45:1 e 130:1. No entanto, a querosene só passa a queimar de forma eficiente, ou próximo disso, estando a uma proporção de 15:1, por isso o combustível deve ser queimado com apenas parte do ar que entra na câmara, na chamada zona de combustão primária. Isto é conseguido por meio de um tubo de chama (camisa de combustão) que tem vários dispositivos para regular a distribuição do fluxo de ar ao longo da câmara (ROLLS ROYCE, 1986).

Desta forma, o restante do ar é direcionado para as áreas externas (Figura 10) com o objetivo de resfriar o sistema, fazendo as turbinas operarem em temperaturas adequadas de funcionamento, e auxiliar na preservação do material.

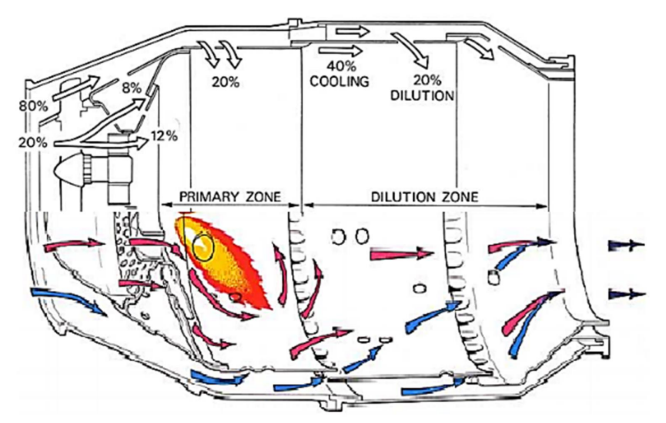

Figura 10 - Câmara de Combustão. (Fonte: Adaptado de ROLLS ROYCE, 1986).

Com isso, alguns parâmetros podem ser delimitados no projeto de uma câmara de combustão, sendo eles: aumento da temperatura $(T 3 \rightarrow T 4)$, eficiência de combustão, perda de pressão total (diminuição da pressão dinâmica em detrimento do aumento da pressão estática), e o limite de emissão de NOx (Óxidos de Nitrogênio), sendo, este último, um parâmetro crucial para a validação do projeto do combustor, disposto no REGULAMENTO BRASILEIRO DA AVIAÇÃO CIVIL, RBAC nº 34, Emenda nº 04, da ANAC.

Em um estudo da NASA, realizado em parceria com as fabricantes General Electric e Pratt \& Whitney, disposto em AGARD - CP537, Technology Requirements for Small Gas Turbines, foram apresentados graus de emissões de NO, como funções da temperatura de entrada do incinerador, pressão, tempo de combustão e temperatura de saída. É possível observar resultados do estudo na Figura 11, onde a base para os dados da GE são as emissões de NOx do modelo ECCP NASNGE (Experimental Clean Combustor Program), e a base para os dados de Pratt \& Whitney é o PW2037. 


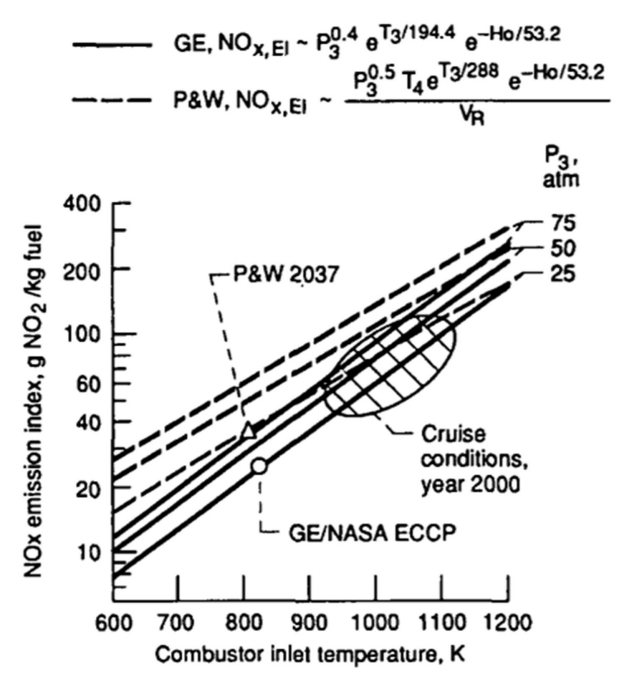

Figura 11 - Óxidos de nitrogênio em função da temperatura e pressão de entrada do combustor. (Fonte: DEVELOPMENT, 1994).

Ainda segundo o requerimento, a dependência mais forte é da temperatura de entrada, onde, aproximadamente, para um aumento de $200 \mathrm{~K}$ na temperatura de entrada, duplica (correlação PW) ou triplica (correlação GE) as emissões de NOx. Isso leva os projetistas a uma limitação na busca pelo aumento da eficiência térmica do motor, já que, como foi apresentado, esta depende do aumento da pressão e temperatura de entrada do combustor.

Algumas soluções são apresentadas pelos projetistas da GE para a solução da dicotomia entre eficiência térmica e menor emissão de gases poluentes: queima rica e queima pobre. Esses dois conceitos se baseiam na composição da mistura ar combustível, com maior ou menor ar presente na zona primária da câmara. A queima rica (Rich Burn) se configura em um processo rápido e uniforme de combustão, passando, rapidamente, pela zona estequiométrica (níveis ideais para a o aproveitamento do ar e combustível injetado) da mistura, sendo este o pico de emissão de NOx e outros gases, para uma mistura pobre na zona secundária, onde a mistura se encontra com uma alta incidência de ar vinda dos compressores, que faz o arrefecimento rápido do ar-combustível. Tal processo é apresentado na Figura 12:

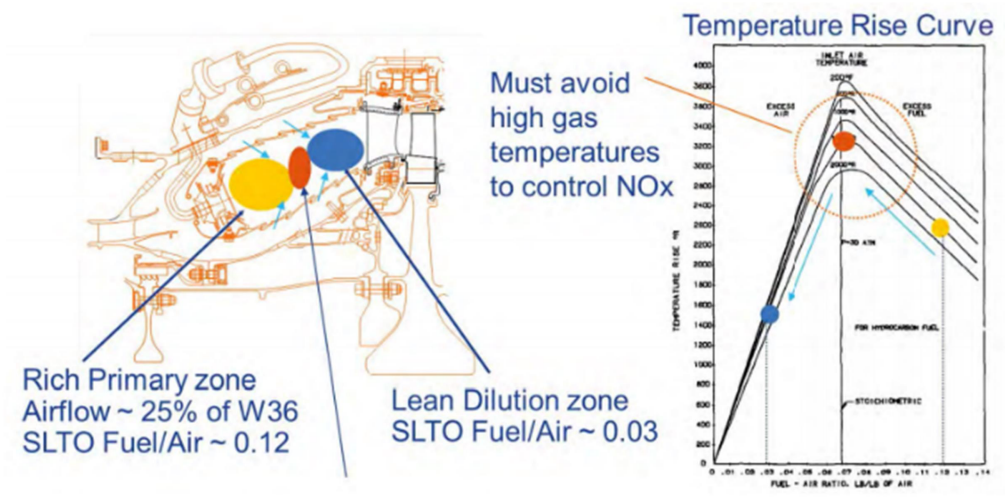

Figura 12 - Combustão com queima quente. (Fonte: Stickles \& Barrett, 2013).

Com relação à queima pobre (Lean burn), ela se baseia em um sistema composto por um injetor piloto e um conjunto de jatos radiais que alimentam a mistura com grande quantidade de ar, empobrecendo-a em regimes de alta potência. Olhando para o gráfico apresentado na Figura 13, é possível observar uma injeção de combustível a níveis que não ultrapassam o pico de maior emissão de NOx.

Persp. Online: exatas \& eng., Campos dos Goytacazes, 34(11) 18 -43-2021

https://ojs3.perspectivasonline.com.br/ 


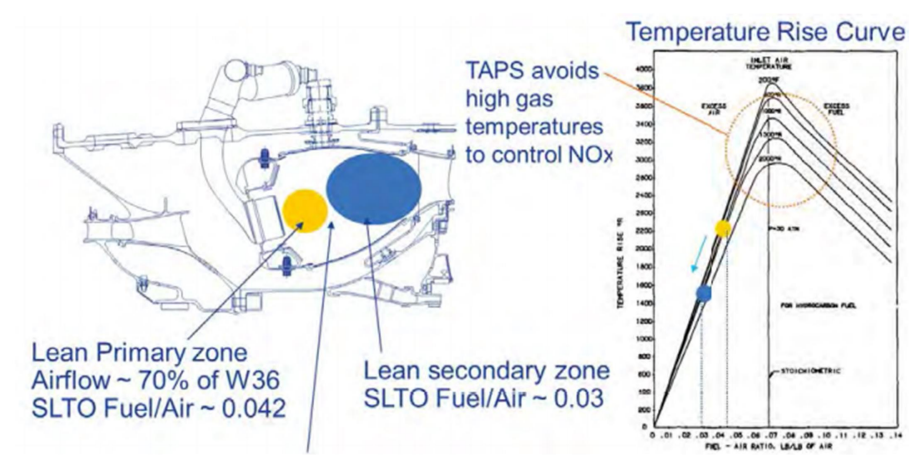

Figura 13 - Combustão com queima pobre. (Fonte: Stickles \& Barrett, 2013).

O equacionamento da câmara de combustão se dá pela razão entre o fluxo de mássico de ar e combustível:

$$
f=\frac{W_{3}}{W_{F}}
$$

Onde $W_{f}$ é a vazão de combustível injetado na câmara.

Por meio da conservação da energia e em termos de pressão e calor específico, é possível determinar razão de fluxos $f$ :

$$
f=\frac{\frac{T_{4}}{T_{3}}-1}{\frac{\eta_{b} L H V}{c_{p} T_{3}}-\frac{T_{4}}{T_{3}}}
$$

Sendo $\eta_{b}$ a eficiência da câmara e $L H V$ o poder calorífico inferior do combustível em $M J / k g$.

Os produtos de combustão são expelidos para as turbinas (estações 4 a 5 na padronização internacional), que nos motores CFM56-7B da GE são divididos em dois grandes estágios, as Turbinas de alta pressão (HPT - High Pressure Turbine) e de baixa pressão (LPT - Low Pressure Turbine). Esses componentes são responsáveis por expandir o gás a alta pressão e temperatura, convertendo em trabalho de eixo, e, assim, alimentar os compressores e o fan a partir de ligações mecânicas de eixo denominadas de $\mathrm{N}_{1}$ (ligação entre os componentes de baixa pressão do motor: Fan, LPC e LPT) e $\mathrm{N}_{2}$ (ligação entre os componentes de alta: HPC e HPT), como demonstrado na Figura 14.

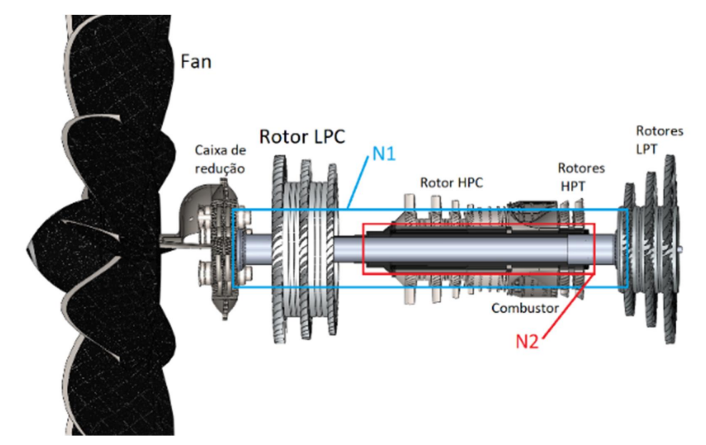

Figura 14 - Ligação entre os componentes de alta e baixa.

Persp. Online: exatas \& eng., Campos dos Goytacazes, 34(11) $18-43-2021$

https://ojs3.perspectivasonline.com.br/ 
Os motores modernos, como por exemplo os da Família PW1000, possuem uma caixa de redução entre o booster e o fan para otimizar as rotações da fan blade, o que impacta, consideravelmente, nos números de estágios dos compressores e turbinas de baixa, já que, com menores solicitações do fan, não se faz necessário distribuir o carregamento em grandes números de estágios.

Cada estágio de turbina é também composto por um estator (NGV - Nozzle Guide Vane) e um rotor. Contudo, diferente dos compressores, esses componentes possuem características particulares, como mostrado na Tabela 2:

Tabela 2 - Propriedades Termodinâmicas do escoamento na turbina. Fonte: Walsh \& Fletcher (2004).

\begin{tabular}{ccc}
\hline Propriedades & Estator (NGV) & Rotor \\
\hline Pressão Estática & Decréscimo & Decréscimo \\
Pressão total & Pequeno decréscimo & Decréscimo \\
Temperatura Estática & Acréscimo & Acréscimo \\
Temperatura total & Constante & Decréscimo \\
Velocidade Absoluta & Acréscimo & Decréscimo \\
Entalpia & Constante & Decréscimo \\
Densidade & Decréscimo & Decréscimo \\
\hline
\end{tabular}

Assim como nos compressores, esses componentes possuem mecanismo de perda relativo a dissipações viscosas, escoamentos secundários e choques que, de uma certa forma, reduzem a eficiência do processo. Conduto, nas turbinas, esses componentes possuem maiores solicitações em relação à temperatura, sendo a TET (Temperatura de Entrada de Turbina) um dos principais parâmetros de projeto, considerado um segredo industrial pelas fabricantes de motores devido ao seu importante papel no desempenho do motor com grande influência na eficiência térmica do ciclo. No gráfico da Figura 15, apresentado pela National Aerospace Laboratory, é possível visualizar a evolução dos níveis de temperatura de entrada ao longo da história até os motores modernos, como GE 90 e o PW4000 com temperaturas em torno de $1500{ }^{\circ} \mathrm{C}$ (quase $1800 \mathrm{~K}$ ).

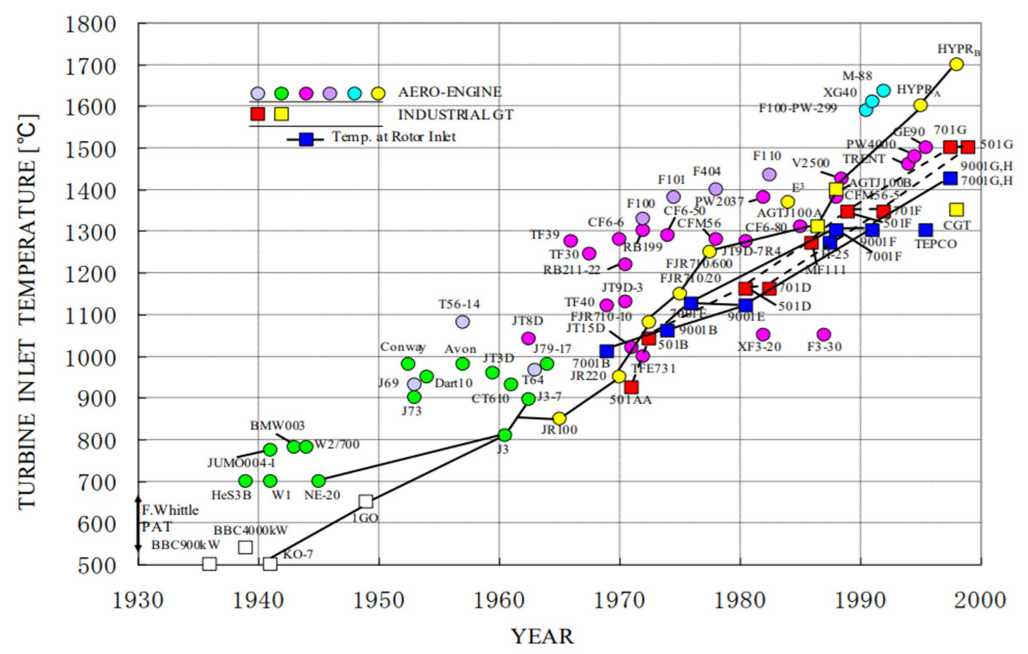

Figura 15 - Temperatura de entrada de Turbina ao longo dos anos. (Fonte: LS000L, 1981).

Persp. Online: exatas \& eng., Campos dos Goytacazes, 34(11) 18 -43-2021

https://ojs3.perspectivasonline.com.br/ 
Esses níveis de temperatura só são possíveis com o desenvolvimento de tecnologias avançadas de materiais e um sistema de refrigeração que sangra o ar dos compressores para o resfriamento dos rotores e estatores da turbina, permitindo que ela opere acima do ponto de fusão do metal que, segundo Scarpin \& Cavazana (2016), nos motores mais modernos, com metalurgias baseadas em cristalização única dos aerofólios, possuem uma capacidade em volta de 1300 a $1400 \mathrm{~K}$. Os aerofólios modernos são projetados com pequenos orifícios por onde o ar proveniente do compressor é expelido, formando uma fina camada de proteção chamada de film cooling. Com isso, o ar, por ser um ótimo isolante térmico, protege as vanes e as blades, evitando fadigas térmicas e taxas descontroladas de expansão e contração dos componentes. O Fluxo do ar de refrigeração é demonstrado na Figura 16:
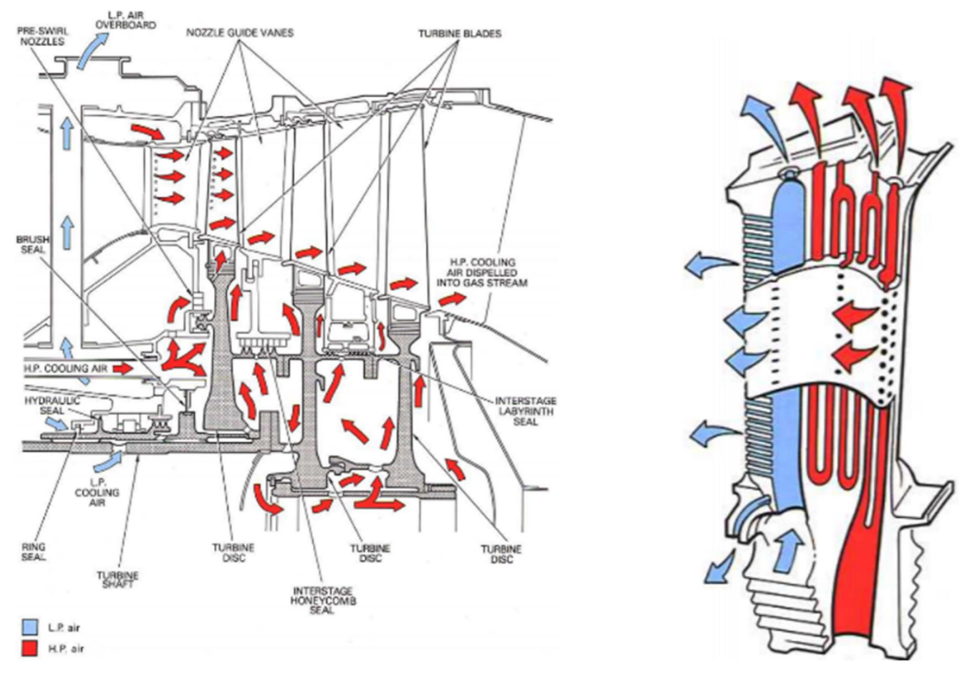

Figura 16 - Sistema de refrigeração. (Fonte: ROLLS ROYCE, 1986).

Analisando em termos de eficiência total, devido a utilização ainda de tecnologias de resfriamento com sangria de ar, grandes níveis de TET correspondem a grandes vazões de ar do compressor, o que afeta a eficiência isentrópica do componente. Existem novos estudos realizados pela NASA para a adição de materiais cerâmicos no revestimento das palhetas, o que minimizaria esses efeitos.

O equacionamento da pressão de entrada da turbina pode ser encontrado a partir da pressão de saída do compressor vezes a pressão perdida na cabine de combustão, ou seja:

$$
P_{4}=P_{3} P R_{b}
$$

Já a temperatura de saída da turbina, tanto de alta quanto de baixa pressão, pode ser obtido a partir da derivação da conservação da energia dos compressores, ligados em eixo, expresso da seguinte forma, em termos de vazão de entrada e calores específicos:

$$
T_{45}=\frac{c p_{41} T_{41}-\frac{W_{25}}{W_{41}}\left(c p_{3} T_{3}-c p_{25} T_{25}\right)}{c p_{45}}
$$

E a pressão de saída é expresso a partir da derivação de eficiência isentrópica da turbina:

Persp. Online: exatas \& eng., Campos dos Goytacazes, 34(11) $18-43-2021$

https://ojs3.perspectivasonline.com.br/ 


$$
P_{45}=P_{41}\left[1-\frac{1}{\eta_{t}}\left(1-\frac{T_{45}}{T_{41}}\right)\right]^{\frac{\gamma_{t}}{\gamma_{t}-1}}
$$

E, de forma análoga, são encontradas as pressões de entrada e saída da turbina de baixa, partindo da energia dos compressores de baixa e fan.

Por fim, o bocal exaustor funciona como um acelerador dos gases expelidos pela turbina, ainda com grandes temperaturas, para gerar propulsão. De forma oposta aos bocais de admissão, os exautores convertem a entalpia em velocidade do escoamento, que, para regimes subsônicos $(M a c h>1)$, são utilizados bocais convergentes. Igualmente, são os mecanismos de perda, caracterizados por efeitos viscosos.

\section{METODOLOGIA}

O estudo de caso do presente artigo será baseado em uma análise de eficiência térmica de um motor aeronáutico, valendo-se das respostas do software de simulação de performance Gasturb 13, desenvolvido por Joachim Kurzke, um dos softwares padrões para estudos em academias e algumas indústrias.

Nesse Software, serão introduzidas premissas retiradas de artigos, livros e sites de fabricantes, referências confiáveis para obtenção de dados consistentes e que validam o modelo de forma bem representativa. Estes dados foram levantados com foco no motor aeronáutico GE90-94B, que equipa o Boeing 777 - 200 e 777-300, certificado em 1995, avaliados em 94.000 libras de empuxo em decolagem (potência máxima no nível do mar) e peso seco de $17400 \mathrm{lbs}(7895 \mathrm{~kg})$.

O estudo de caso se dará partindo da coleta de informações sobre o motor, dentro dos parâmetros do ponto de projeto TOC (Top of climb - Topo de subida): Número de Mach de 0.8 , altitude de $35.000 \mathrm{ft}$ (10.668 metros), Atmosfera ISA (International Standard Atmosphere - Atmosfera Padrão), além de BPR, OPR, Tração Líquida (FN), TSFC (Thrustspecific fuel consumption - consumo específico de combustível por unidade de tração) não instalado, ou seja, sem extrações de potência para componentes pneumáticos e mecânicos, e o Poder calorífico do combustível, de modo a gerar as premissas do modelo no ponto de projeto (on designe) e avaliar as respostas do Software para validação do motor.

A interface do Software Gasturb 13 e os dados de entrada com suas respectivas referências são apresentados nas Figuras 17 e 18: 


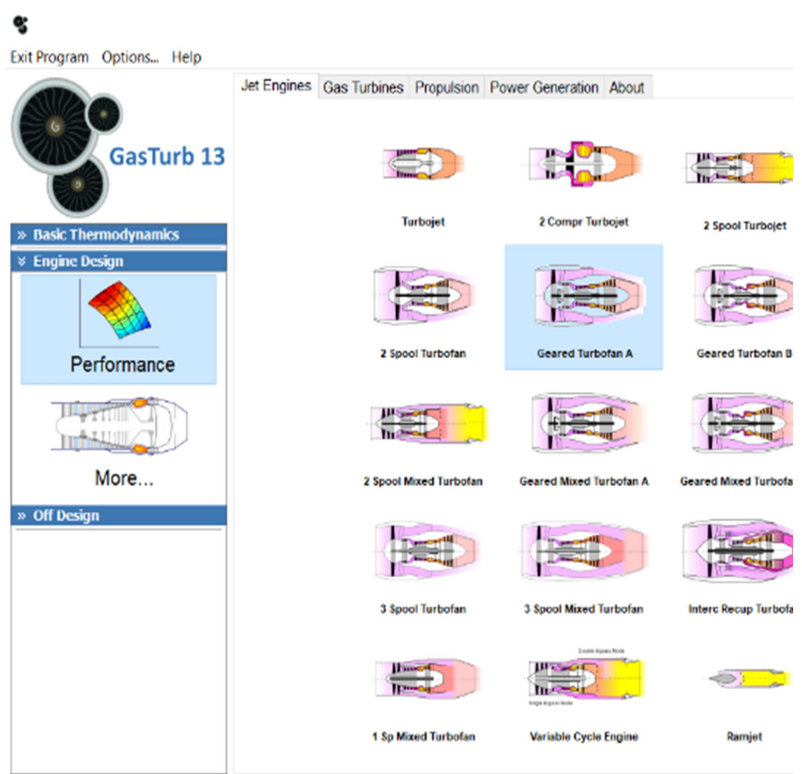

Figura 17 - Interface do Gasturb 13.

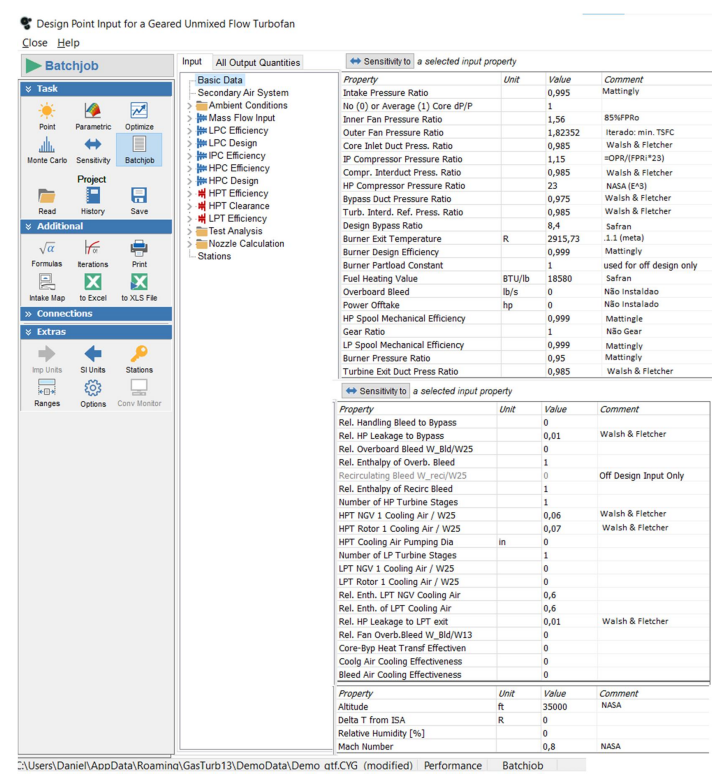

Figura 18 - Dados de Entrada.

Após gerada a análise, obteve-se os resultados no ponto de projeto (Figura 19):

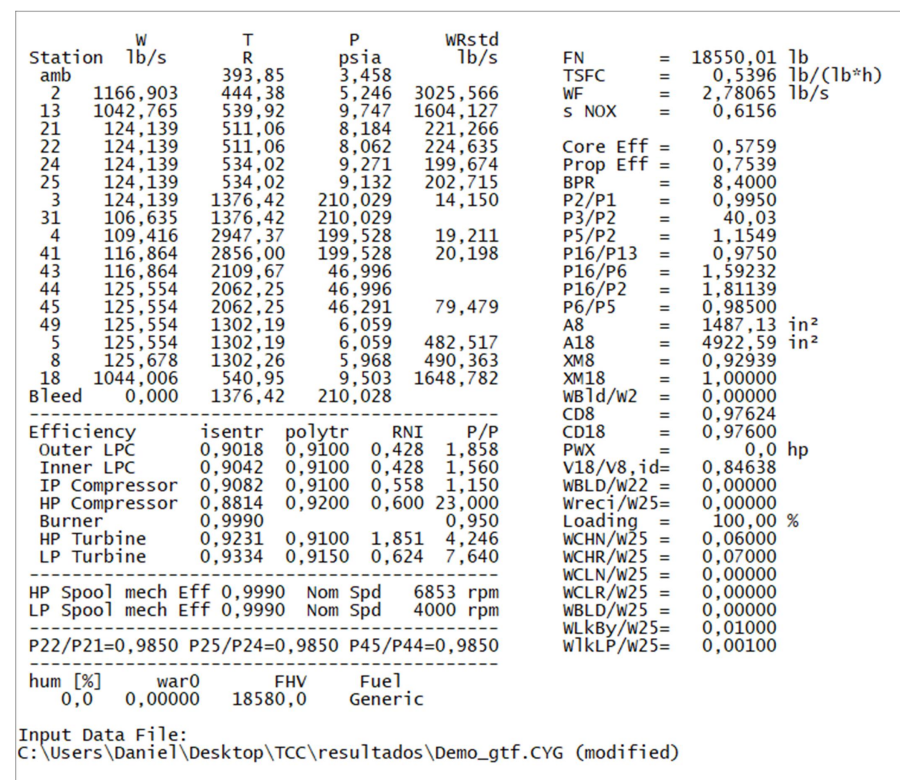

Figura19- Saídas no Software.

A validação do modelo foi obtida comparando o TSFC, retornado pelo Software de $0,5396 l b /(l b . h)$, como informado no gráfico disponibilizado por uma fonte de pesquisa da NASA (Figura 20), apresentando uma diferença de menos de 2 por cento, além da convergência para a tração objetivada de $18550 \mathrm{lbf}(81,514 \mathrm{KN})$, indicada no catálogo do fabricante, disponibilizado pela SAFRA

(Figura 21): 
State-of-the-Art Subsonic Engine SFC

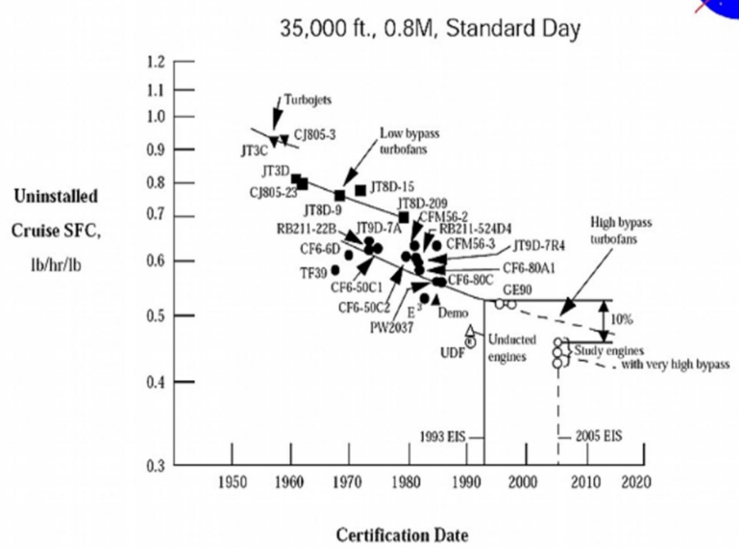

Figura 20 - Evolução da performance do TSFC dos motores subsônicos. (Fonte: Kopp, 2010).

\section{ENGINE FEATURES}

\begin{tabular}{|c|c|c|}
\hline & $-94 B$ & $-115 B$ \\
\hline Max. takeoff thrust (lb) & 93,700 & 115,300 \\
\hline Bypass ratio & 8.40 à 9 & 9 \\
\hline Flat rate temperature $\left({ }^{\circ} \mathbf{F}\right)$ & $\begin{array}{c}86 \\
\left(30^{\circ} \mathrm{C}\right) \\
\end{array}$ & $\begin{array}{c}86 \\
\left(30^{\circ} \mathrm{C}\right) \\
\end{array}$ \\
\hline $\begin{array}{l}\text { Max. climb thrust (kN) } \\
35000 \mathrm{ft} \text { - Mach } 0.84 \text { - ISA } \\
\text { engine installed }\end{array}$ & 18,562 & 22,383 \\
\hline $\begin{array}{l}\text { Overall pressure ratio } \\
\text { at max. climb }\end{array}$ & 40 & 42 \\
\hline Length (in) & 287 & 287 \\
\hline Fan diameter (in) & 134 & 135 \\
\hline Applications & $\begin{array}{l}\text { B777-200 } \\
\text { B777-200ER }\end{array}$ & $\begin{array}{l}\text { B777-200LR } \\
\text { B777-300ER }\end{array}$ \\
\hline
\end{tabular}

Figura 21 - Premissas do motor GE90. (Fonte: Safran, 2011).

Com base no ponto de projeto, foi possível dar início ao estudo do desempenho propriamente dito, pois ele utiliza o ponto de projeto como referência para a simulação dos pontos fora do ponto de projeto (Off designe), já que, durante todo o envelope de voo do avião, o motor é submetido a diferentes exigências, como sugere Avellan (2011), que acrescenta mais dois pontos de máximo desempenho além do TDP (Ponto de projeto Térmico), já citado neste artigo:

a) Ponto de Projeto Aerodinâmico (ADP): condição mais demandante em termos de vazão, como por exemplo em topo de subida;

b) Ponto de Projeto energético (EDP): condição na qual ele deve ser mais eficiente, usualmente em cruzeiro.

Diferentemente do cicle reference point, para uma análise fora do ponto de projeto faz-se necessário o uso de mapas de desempenho dos componentes (Fan, LPC, HPC, HPT e LPT), além de correções desses mapas em condições termodinâmicas, como: temperatura, pressão, vazões mássicas, entre outras que possibilitam uma análise mais aproximada possível do motor GE90-94B em diferentes condições de operação, onde são variados os termos de altitude, Mach, TSFC, razão de by-pass etc. Essas correções fazem-se necessárias, tendo em vista a grande dificuldade de se obter mapas de desempenho de motores no domínio público, devido a confidencialidade por meio dos fabricantes, recorrendo, assim, ao uso dos mapas de desempenho mais representativos do motor para a configuração selecionada (Geared Turbofan A ). Mapas estes disponibilizados na própria biblioteca do Software Gasturb 13.

Para tais correções, faz-se uso de números adimensionais, como: número de Mach, número de Reynolds, e coeficiente isentrópico, que minimizam as variáveis e convergem as equações para a condição desejada. Estes dois últimos adimensionais são definidos, respectivamente, como:

$$
\begin{gathered}
R e=\frac{D V \rho}{\mu} \\
\gamma=\frac{C_{p}}{C_{v}}
\end{gathered}
$$

Persp. Online: exatas \& eng., Campos dos Goytacazes, 34(11) $18-43-2021$

https://ojs3.perspectivasonline.com.br/ 
Onde $R e$ é a razão entre as forças de inércia - caracterizado como o produto do diâmetro de vazão (D), velocidade média (V) e a densidade do fluido $(\rho)$ - e as forças viscosas (viscosidade dinâmica $\mu$ ), e $\gamma$ a razão entre o calor específico, a pressão constante e o calor específico em volume constante.

Corrigindo os mapas e plotando os gráficos de eficiência, é possível alcançar os efeitos gerados pela equação base para a análise da eficiência térmica de motores aeronáuticos proposta por Ribeiro (2012), o qual afirma ser definida como:

$$
\eta_{t h}=\frac{\Delta \dot{E} c}{\dot{m}_{f} P C I}
$$

Onde o numerador $\Delta \dot{E} C$ é a variação da energia cinética do motor, ou seja:

$$
\Delta \dot{E C}=\frac{1}{2} \dot{m}\left(V_{9}{ }^{2}-V_{0}{ }^{2}\right)
$$

E o denominador da expressão é o potencial químico, sendo $\dot{m}_{f}$ o fluxo mássico de combustível, e PCI o poder calorífico inferior, que é definido como o poder calorífico total menos a parcela necessária para a transformação latente do ar de estado líquido para gasoso.

\section{RESULTADOS E DISCUSSÕES}

O primeiro estudo de eficiência foi realizado fixando a temperatura atmosférica ISA e a temperatura de entrada de turbina, esta última em $2916 \mathrm{R}\left(1396,85^{\circ} \mathrm{C}\right)$ e variando os termos de altitude e número de Mach para regiões de eficiência térmica. O gráfico gerado pode ser visualizado na imagem da Figura 22:

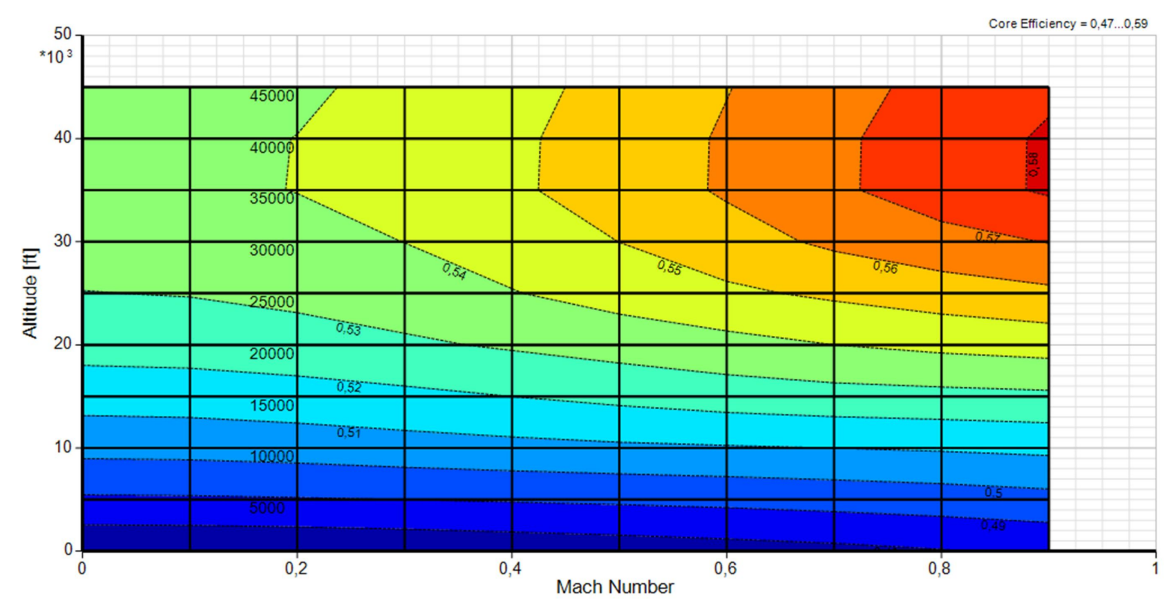

Figura 22 - Regiões de eficiência térmica para variações de Altitude e número de Mach.

Ao analisar o gráfico para uma altitude constante em 40 mil pés, é possível notar um aumento da eficiência térmica com o aumento da velocidade, isso porque, nessas altitudes, ocorre o efeito da compressibilidade, ou seja, com o aumento da velocidade do avião, tem-se uma "pressão virtual" sendo gerada na admissão de ar pelo aumento da quantidade de movimento, elevando a pressão total do ciclo. Contudo, em baixas altitudes, é possível perceber uma região de eficiência constante com o aumento da velocidade. Essa característica pode ser explicada com o gráfico apresentado na Figura 23, onde se tem o

Persp. Online: exatas \& eng., Campos dos Goytacazes, 34(11) 18 -43-2021

https://ojs3.perspectivasonline.com.br/ 
aumento da força de arrastro compensado por regiões de maior eficiência, e, em contrapartida, regiões de menor força de arrastro (menor velocidade) compensado por regiões de maior tração do motor.

Já analisando o gráfico da Figura 22, a uma dada velocidade constante, como por exemplo em Mach 0.8, é possível observar o aumento da eficiência térmica do motor com o aumento da altitude devido a condições de baixa densidade que diminui o arrastro, e menor temperatura externa que levam a condições de maior eficiência.

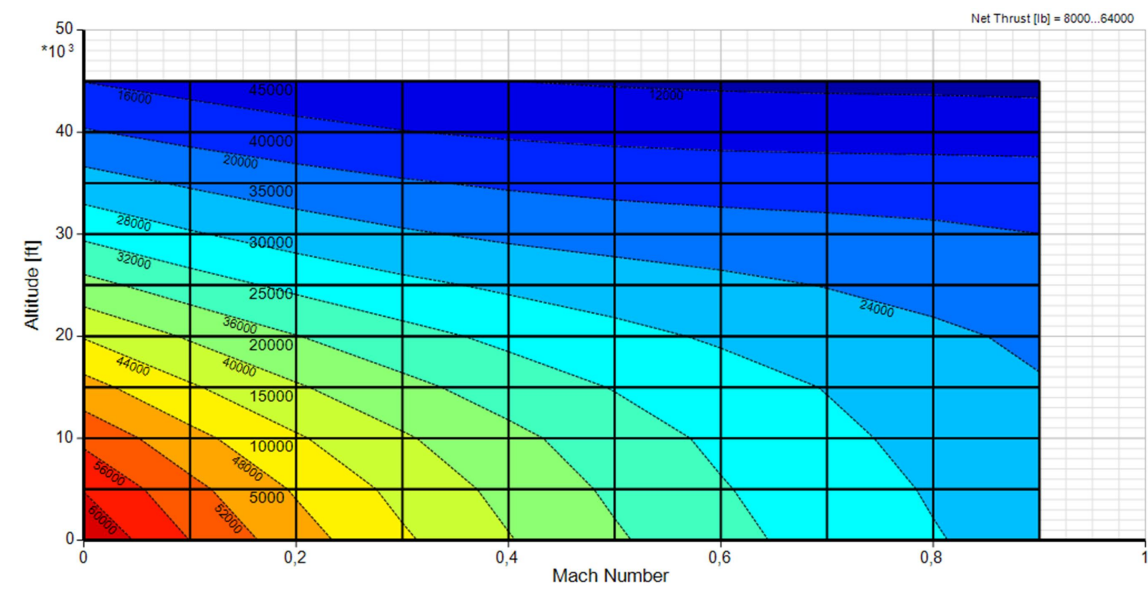

Figura 23 - Regiões de tração para variações de Altitude e número de Mach.

A próxima análise se dá fixando a altitude em regiões de 35000 pés (aproximadamente 11 mil metros), e fixando a temperatura aos mesmos valores do primeiro estudo. As variações serão realizadas sobre o Número de Mach e Poder Calorífico do Combustível (Fuel Heating Value), para regiões de eficiência térmica, representado na Figura 24.

Nesta análise, foi possível obter resultados bem similares com relação a variação do número de Mach, pelos mesmos motivos apresentados acima. Já para um número de Mach fixo, é possível perceber cores mais frias ao deslocar para regiões superiores no gráfico. Isso se dá pois, quanto maior a potência necessária por libra de combustível necessária, menor é a eficiência térmica do motor. Contudo, o ponto de referência GE90 para termos de FHV está em $18500 \mathrm{BTU} / \mathrm{lb}$, isso porque, segundo Silva et al. (2013), quando utilizados combustíveis com poder calorífico mais baixos, maior será o fluxo de combustível necessário e, consecutivamente, maiores taxas de pressão do compressor. Ainda segundo ele, isso reduziria as margens de surge para próximo da linha de operação do compressor, fazendo com que ele opere em condições perigosas de funcionamento. 


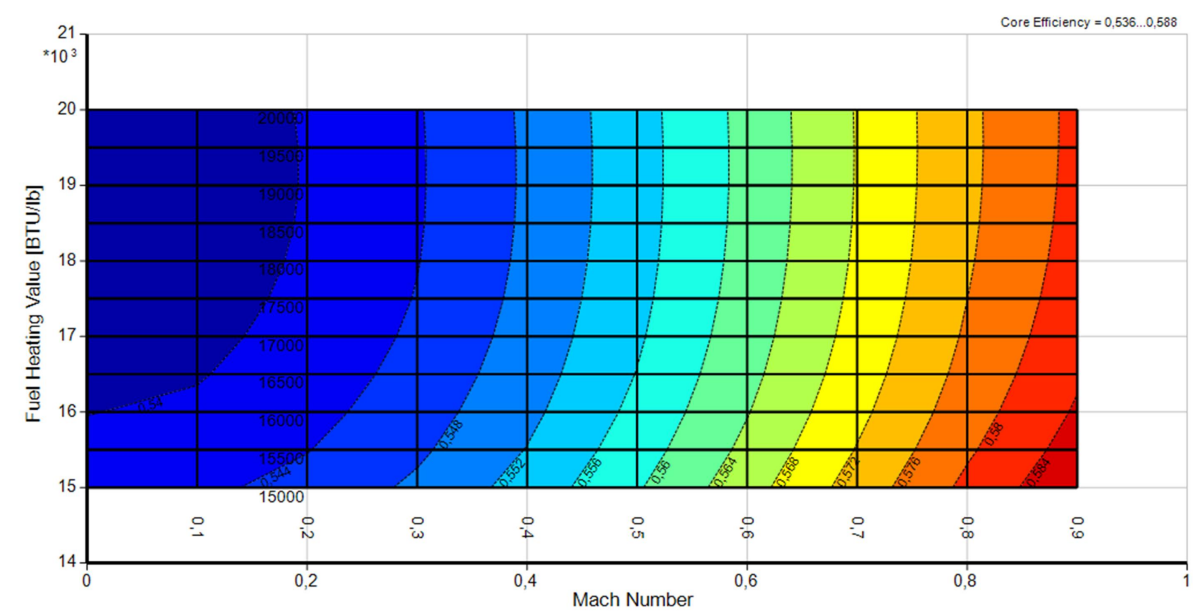

Figura 24 - Regiões de eficiência térmica para variações do FHV e número de Mach.

Um outro gráfico importante é o apresentado na Figura 25, que analisa efeitos na eficiência térmica a partir de variações do potencial calorífico do combustível e do Overboard Bleed, sendo este especificado pela ANAC como sangrias de ar do compressor, ou seja, a quantidade de ar que é desviado para outros fins já citados neste artigo. Com isso, é possível observar que quanto maior a quantidade de ar sangrado do compressor (regiões superiores no gráfico), apesar de auxiliar no controle do estol devido ao alívio de pressão, este desvio resulta em regiões de menor eficiência provocados pela disfuncionalidade do componente, já que, aliviar a pressão do compressor é diminuir sua capacidade compressiva, o que, consecutivamente, provoca uma diminuição drástica da eficiência térmica do motor em mais de $10 \%$ para cada 28 a 29 libras por segundo de ar que entra nas regiões quentes, e esse efeito se atenua com o aumento do potencial calorífico do combustível, devido a maior necessidade de ar de refrigeração.

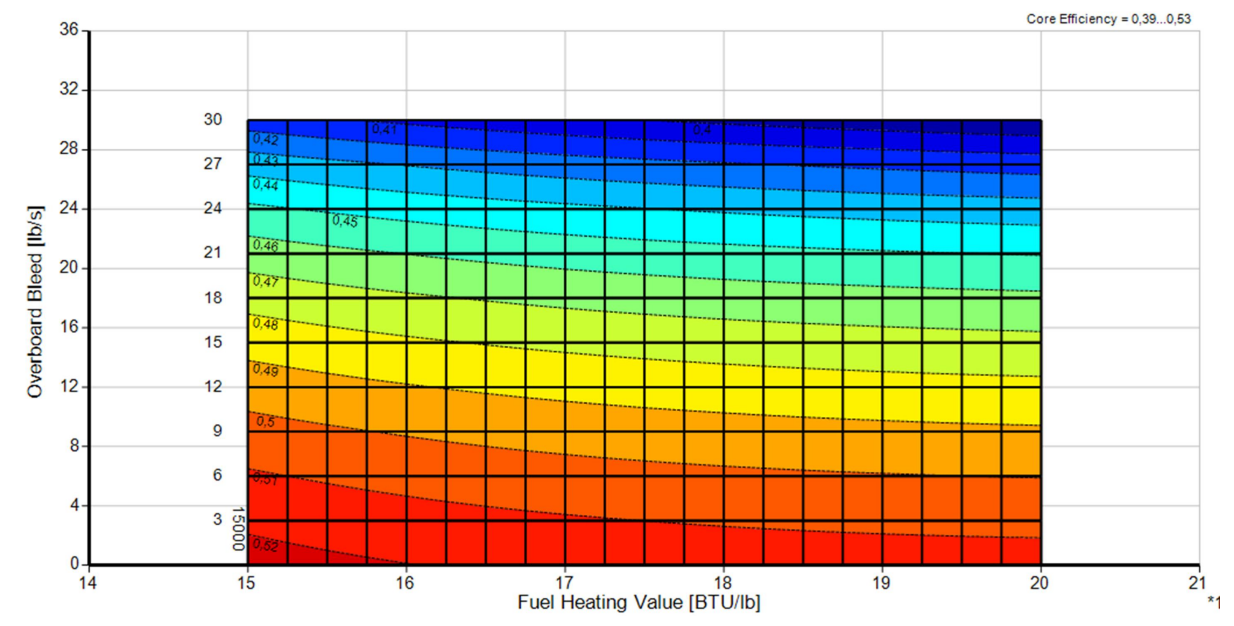

Figura 25 - Regiões de eficiência térmica para variações do FHV e Overboard Bleed

Os gráficos apresentados autenticam o proposto pela Equação 23 descrita neste artigo, demonstrando o comportamento da eficiência térmica relacionada diretamente à energia cinética do fluxo, e relacionada inversamente ao potencial químico inserido no motor por meio do fluxo de combustível e seu poder calorífico.

Um outro ponto analisado foi o TSFC, que em baixos índices, caracteriza um motor com baixo consumo de combustível, desta forma pode ser confundido com razões de

Persp. Online: exatas \& eng., Campos dos Goytacazes, 34(11) $18-43-2021$

https://ojs3.perspectivasonline.com.br/ 
eficiência em termos térmicos. Contudo, a partir do gráfico da Figura 26, é possível identificar que os menores SFCs estão em regiões diferentes (à esquerda no gráfico) das regiões de eficiência térmica analisados anteriormente no gráfico da Figura 22, para os mesmos parâmetros de número de Mach e altitude:

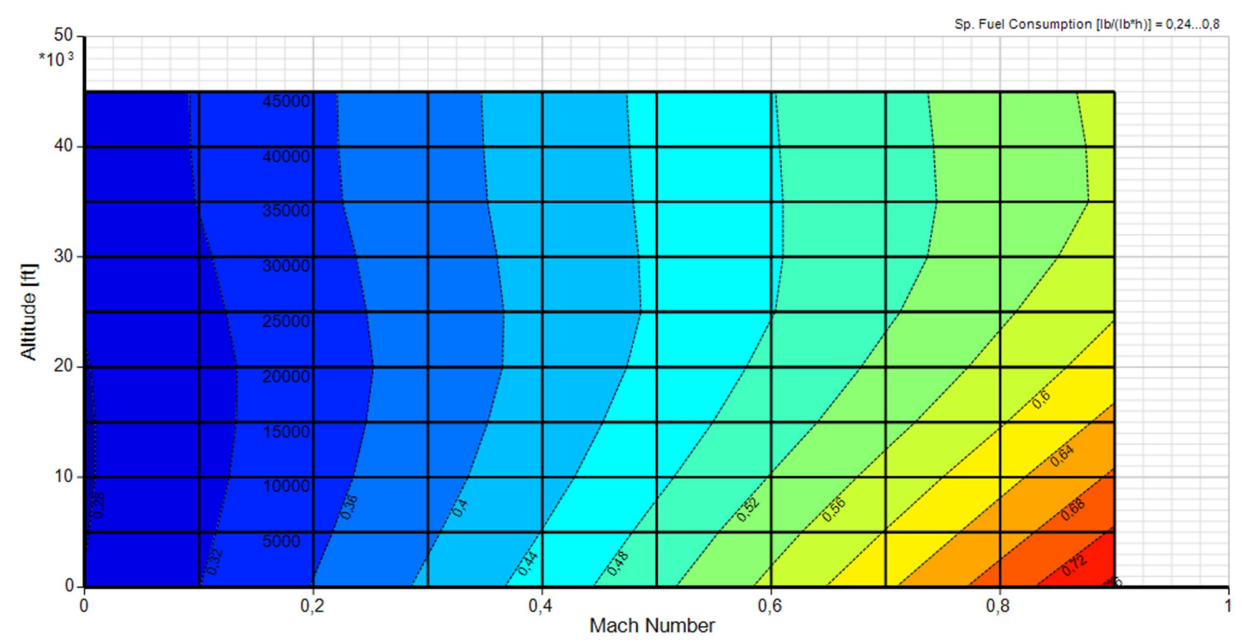

Figura 26 - Regiões de SFC para variações de Altitude e Número de Mach.

As cores mais quentes indicam regiões de maior consumo que se localizam no canto inferior direito do gráfico, isso se dá, pois, como já explicado, quanto maior a velocidade em baixas altitudes, maior o arrastro, e, dessa forma, maior a solicitação de combustível necessária.

Com isso, é possível analisar que um baixo consumo específico de combustível nem sempre deve ser definido como eficiência. Essa associação é válida apenas quando são comparados motores diferentes em um mesmo ponto de projeto, ou seja, em um mesmo parâmetro de altitude e velocidade, como apresentado na Equação 25:

$$
\eta_{\text {overall }}=\frac{V_{0}}{T S F C * P C I}
$$

que define eficiência total do motor $\left(\eta_{\text {overall }}\right)$ a partir do TSFC, do poder calorífico PCI e velocidade de entrada prescrita $\left(V_{0}\right)$.

\section{CONCLUSÕES}

O presente artigo teve como propósito principal estudar os fatores que influenciam na eficiência térmica de um motor aeronáutico tipo Turbofan, em aplicação comercial, analisando-o em um ponto de projeto específico, assim como fora do ponto de projeto (off design). O estudo foi realizado com base no software Gasturb 13, por onde se pode projetar um modelo com foco no motor GE90-94B, validá-lo a partir de comparações dos resultados obtidos com os resultados especificados em materiais confiáveis, como: artigos, dissertações, manuais e pesquisas, todos bem referenciados, autenticando os dados de entrada e permitindo variações de análises.

Após realizado o estudo, foi possível obter importantes conclusões sobre o comportamento do motor quando submetido a variações de operação, como números de

Persp. Online: exatas \& eng., Campos dos Goytacazes, 34(11) $18-43-2021$

https://ojs3.perspectivasonline.com.br/ 
Mach e Altitude, os efeitos da compressibilidade do ar para altas velocidades e os impactos do arrastro em baixas altitudes, justificando o ponto de operação de aviões comerciais em cruzeiro, em torno de Mach 0.8 e 40 mil pés, sendo estes parâmetros de maior eficiência térmica para operação, aumentando o desempenho do motor, o que afeta, consideravelmente, nos custos de voo, e, desta forma, ligando o projetista de motores aeronáuticos ao passageiro. Este, por sua vez, exige cada vez mais um transporte acessível.

O estudo se fez importante também para compreender os efeitos de dois parâmetros que mexem com a margem de surge do compressor, essa linha de operação dita como de instabilidade de funcionamento e, por esta razão, muito evitada pelos projetistas. Um desses parâmetros é o potencial calorífico que, como analisado, em baixos níveis, revela um aumento de eficiência térmica, mas também, uma necessidade de maior fluxo de combustível, o que eleva a linha de operação do compressor para próximo da margem de surge. E o outro parâmetro é a sangria de ar, que aparece como solução para corrigir os efeitos da instabilidade gerada por se operar próximo dessas margens. Em contrapartida, ela promove uma ineficiência em termos térmicos do motor aeronáutico. É essa dicotomia que justifica a necessidade dos fabricantes em assegurar a confidencialidade de seus projetos e investimentos em avanços tecnológicos, tornando assim, cada motor único, com a prioridade exclusiva de cada fabricante.

Durante a análise no software Gasturb 13, foi possível compreender também a importância não só de bons dados de entrada, os quais foram essenciais para o estudo de caso (e para um projeto de motor aeronáutico como um todo), mas também a compreensão dos fatores que influenciam no comportamento das variáveis a serem iteradas, ou seja, para se obter a resposta adequada para aquele ponto de projeto especificado, foi necessário modificar valores, como a temperatura de saída da câmara, até que a tração e temperatura de entrada de turbina convirja para os valores encontrados nas referências e assim obter respostas condizentes com o estudo em questão.

Apesar das diversas arquiteturas pré-prontas, apresentadas na interface do software Gasturb 13, demonstrou-se ser possível modelar diversas outras configurações, já que o motor em estudo, GE90-94B, não apresentava uma caixa de redução na saída do fan (como no caso do modelo apresentado Geared Turbofan pelo software). Para isso, foram realizadas tais modificações de entrada sem perder a confiabilidade das respostas.

Com a elaboração deste artigo, foi possível compreender o quanto se avançou nas técnicas de aprimoramento do desempenho térmico do motor, que vão desde simples tecnologias que impedem a ingestão de objetos que possam prejudicar o seu bom funcionamento, até o estudo de materiais altamente complexos, como os de granulometria única que permitem uma maior resistência a altas temperaturas, além de tecnologias de designs de blades e vanes que possibilitam uma melhor performance de cada componente, de acordo com sua solicitação e resfriamento adequado diante dos limites térmicos. Desta forma, este artigo propõe um estudo aprofundado de tais tecnologias, e como elas influenciam, consideravelmente, não só na eficiência térmica do motor, mas também em seu desempenho propulsivo.

\section{REFERÊNCIAS}

Persp. Online: exatas \& eng., Campos dos Goytacazes, 34(11) 18 -43-2021

https://ojs3.perspectivasonline.com.br/ 
AVELLAN, R. Sobre o design de motores aeronáuticos com eficiência energética: algumas inovações recentes. [S.1.: s.n.], 2011.

BROWN T. L.; LEMAY JR, EUGENE H.; BUSTER B.; JULIA R. Quimica: la ciencia central [S.1.: s.n.], 2004.

DESCARTES, R. Discours de la Méthode (Geometry Analytique). [S.1.: s.n.], 1637.

DEVELOPMENT, ADVISORY GROUP FOR AEROSPACE RESEARCH. Technology Requirements for Small Gas Turbines. Cp 557. São Paulo: Cortez, 1994.

DOKUMEN.T. Fluxo de ar do motor CFM56-7B. 2021. Disponível em: $<$ https://dokumen.tips/documents/cfm56-7b-sac-engine-airflow.html $>$. Acesso em: 17 de junho de 2021.

GIAMPAOLO, A. Compressor handbook: principles and practice. [S.1.]: CRC Press, 2020 .

JENSEN, W. B. A constante universal de gás r. v. 80, n. 7, 2003.

KOPP, C. Avaliando o impacto das leis de crescimento exponencial no projeto de aeronaves de combate futuras. 2010.

LS000L, G. G. Technical report (of national aerospace laboratory). 1981.

NIHONKOKU S. WIKI. Jet Engine. 2021. Disponível em: <https://nihonkokushoukan.fandom.com/wiki/Jet_Engine>. Acesso em: 17 de junho de 2021.

RAJADURAI, J. S. Thermodynamics and Thermal engineering. [S.1.]: New Age International, 2003.

REIS, V. dos. Sistema de Admissão e Escapamentos. Santa Catarina: AEROTD, 2015.

RIBEIRO, P. M. A. Análise de performance da Família de Motores de Avião CFM56. Tese (Doutorado), 2012.

ROYCE, PLC ROLLS. The Jet Engine. [S.1.]: Derby, 1986.

SAE ARP 755D. Gas Turbine Engine Performance station Identification and Nomenclatu. 2014.

SAFRAN, S. Commercial Aircraft Engines Ge90. [S.1.], 2011. Disponível em: $<$ https://www.safran-aircraft-engines.com/sites/snecma/files/fiche_ge90_ang.pdf $>$. Acesso em: jun. 2021.

SCARPIN, L. M.; CAVAZANA, G. C. Análise termodinâmica de uma turbina a gás aeronáutica operando com metano. Revista Engenharia em Ação UniToledo, v. 1, n. 01, 2016.

SHAPIRO, H. N; MORAN, M. J. Princípios de termodinâmica para engenharia. LTC, Ed, v. 6, 2009.

SILVA, EB et al. Gas turbine performance analysis operating with lowheating value fuels. Revista de Engenharia Térmica, v. 12, n. 2, p. 08-15, 2013.

STICKLES, R; BARRETT, J. Taps ii combustor final report. Continuous Lower Energy, Emissions and Noise (CLEEN) Technologies Development, Federal Aviation Administration, 2013.

WALSH, P. P; FLETCHER, P.. Gas turbine performance. [S.1.]: John Wiley \& Sons, 2004.

Persp. Online: exatas \& eng., Campos dos Goytacazes, 34(11) $18-43-2021$

https://ojs3.perspectivasonline.com.br/ 